\title{
ANÁLISE DO TURISMO SOB O ENFOQUE SISTÊMICO: ESTUDO DE CASO DO TERRITÓRIO TURÍSTICO DE FRONTEIRA - PEDRO JUAN CABALLERO/PY E PONTA PORÃ/BR.
}

ANALYSIS OF TOURISM UNDER THE SYSTEMIC APPROACH: CASE STUDY OF BORDER TERRITORY TOURISM - PEDRO JUAN CABALLERO, PARAGUAY AND PONTA PORÃ, BRAZIL. ANÁLISIS DEL TURISMO BAJO EL ENFOQUE SISTÉMICO: ESTUDIO DE CASO DEL TERRITORIO TURÍSTICO DE FRONTERA - PEDRO JUAN CABALLERO / PY Y PUNTA POR A

Veridiana Ribeiro Graduada em Turismo pela Universidade Estadual de Mato Grosso do Sul - UEMS veri_ribeiro@hotmail.com

\section{Dores Cristina Grechi}

Professora e pesquisadora da Universidade Estadual de Mato Grosso do Sul - UEMS cgrechi@uol.com.br

Resumo: Este estudo utilizou a Teoria Geral de Sistemas para analisar o turismo num território de fronteira entre Brasil e Paraguai. De forma inicial realizou-se uma revisão teórica dos autores que já estudaram esta teoria aplicada para o turismo, identificando semelhanças e aspectos complementares entre os mesmos. A pesquisa preocupou-se, ainda, em verificar a aplicabilidade da abordagem sistêmica como método de análise, usando como exemplo o sistema turístico de Mato Grosso do Sul no território de fronteira, especialmente os municípios irmãos, Pedro Juan Caballero/PY e Ponta Porã/BR. A metodologia baseou-se em pesquisa bibliográfica e documental. A partir da consulta em livros, artigos, periódicos e sites institucionais foi possível identificar os elementos do sistema turístico de fronteira e seu respectivo modelo, o qual configura-se num formato único, por ser binacional.

Palavras chave: teoria; sistema; método; turismo; planejamento. 
Abstract: This study used the General Systems Theory to analyze tourism in a border territory between Brazil and Paraguay. Initially, a theoretical review was carried out by the authors who have already studied this applied theory for tourism, identifying similarities and complementary aspects between them. The research was also concerned with verifying the applicability of the systemic approach as a method of analysis, using as an example the tourist system of Mato Grosso do Sul in the frontier territory, especially the sister municipalities, Pedro Juan Caballero / PY and Ponta Porã / BR. The methodology was based on bibliographical and documentary research. From the consultation on books, articles, periodicals and institutional sites it was possible to identify the elements of the border tourist system and its respective model, which is configured in a unique format, because it is binational.

Key words: theory; system; method; tourism; planning.

Resumen: Este estudio utilizó la Teoría General de Sistemas para analizar el turismo en un territorio de frontera entre Brasil y Paraguay. De forma inicial se realizó una revisión teórica de los autores que ya estudiaron esta teoría aplicada para el turismo, identificando semejanzas y aspectos complementarios entre los mismos. La investigación se preocupó, además, en verificar la aplicabilidad del enfoque sistémico como método de análisis, usando como ejemplo el sistema turístico de Mato Grosso do Sul en el territorio de frontera, especialmente los municipios hermanos, Pedro Juan Caballero / PY y Ponta Porã / BR. La metodología se basó en la investigación bibliográfica y documental. A partir de la consulta en libros, artículos, periódicos y sitios institucionales fue posible identificar los elementos del sistema turístico de frontera y su respectivo modelo, el cual se configura en un formato único, por ser binacional.

Palabras clave: la teoría; sistema; método; turismo; planificación

\section{INTRODUÇÃO}

Este estudo resultou de um projeto de pesquisa maior e relacionado ao impacto do turismo no desenvolvimento territorial, o qual desmembrou-se em diversas pesquisas no território turístico da fronteira entre Pedro Juan Caballero - Paraguai (PY) 
e Ponta Porã - Brasil (BR), uma das quais é esta pesquisa cujos resultados serão aqui apresentados. A região em foco localiza-se no sul do estado de Mato Grosso do Sul e se caracteriza pela exploração da agricultura, pecuária e comércio de importados. Este último, bastante estimulado na última década em função do câmbio favorável para os brasileiros no que se refere à compra de produtos estrangeiros.

Um dos propósitos delimitados para a região mencionada foi verificar a aplicabilidade da abordagem sistêmica como método de análise do planejamento e desenvolvimento do turismo, usando como exemplo a caracterização do sistema turístico no território turístico de fronteira, especificamente nos municípios de Pedro Juan Caballero/PY e Ponta Porã/BR separados por fronteira seca ${ }^{1}$. Além disso, procurou-se identificar na literatura pesquisada as diferentes abordagens da análise sistêmica no estudo do turismo e usou-se como referencial teórico o sistema turístico construído por Beni (2001). Na sequência descreveu-se o sistema turístico da região estudada, procedendo à respectiva caracterização do mesmo, sempre usando o sistur proposto por Beni (2001) como referência.

Por se tratar de uma pesquisa documental, a metodologia compreendeu a revisão teórica dando ênfase à abordagem sistêmica. Paralelamente a revisão teórica buscou-se documentos referentes ao turismo e sua organização nos munícipios vizinhos, bem como, o levantamento dos elementos que compõe o sistema turístico (exceto conjunto das relações ambientais) desta região turística composta por Ponta Porã (Brasil) e Pedro Juan Caballero (Paraguai). Após a revisão teórica foi possível identificar convergências e divergências entre os diferentes autores pesquisados, o que facilitou a escolha do referencial que seria utilizado para analisar o sistema turístico na linha de fronteira. Na sequência, pesquisou-se os elementos que compõe o sistema turístico local e obras que já tivessem abordado os diferentes elementos turísticos da região, o que facilitou a apresentação ilustrativa do sistema local e a sua posterior análise e discussão. $\mathrm{O}$ artigo está organizado em duas partes, a primeira trata da abordagem sistêmica e das diferentes aplicações da teoria dos sistemas no turismo, e a segunda parte refere-se à aplicação desta abordagem para a localidade pesquisada.

\footnotetext{
${ }^{1}$ A divisa internacional em lugares que não existem acidentes geográficos como rios, lagos e oceanos e somente uma linha imaginária divide os dois países (ALBUQUERQUE, 2005).
} 


\section{O TURISMO E A ABORDAGEM SISTÊMICA}

Para a Organização Mundial do Turismo - OMT (2001) a prática do turismo envolve o conjunto de atividades que as pessoas realizam durante suas viagens e estadas em lugares distintos de seu entorno habitual, por um período de tempo consecutivo inferior a um ano, com fins de lazer, negócios ou por outros motivos não relacionados ao exercício de atividade remunerada no local visitado. O turismo como atividade produtiva e geradora de emprego "se inclui entre os setores motrizes para o desenvolvimento de certas regiões" e tem se destacado no cenário nacional e internacional (CORREA, 2010, p. 2).

O turismo pode então ser encarado como fenômeno social da modernidade, não é somente uma atividade produtiva ou econômica, mas uma experiência e uma prática social que vem tomando proporções consideráveis na economia moderna, muito disso em razão do aumento do tempo livre, além da redução do custo do transporte aéreo e da facilidade de viajar (BRASIL, 2009). Segundo dados da Organização Mundial do Turismo - OMT, entre 2010 a 2014 as chegadas internacionais no Brasil apresentaram crescimento exponencial, chegando a 6,306 milhões de turistas em 2016 (UNWTO, 2016).

A expressividade econômica da atividade significa que "um conjunto de fatores torna- se vital para fazer com que a atividade dinamize a geração de emprego e renda: boa infraestrutura de transporte, hospedagem, saneamento, comunicação e segurança e divulgação adequada" (BRASIL, 2009:10). Esses componentes interpõe a necessidade de se discutir o turismo como ciência, conforme Lohmann e Netto (2008) apontam.

Definida como indústria sem chaminé, indústria do lazer, indústria do tempo livre, entre outras, a atividade turística recebe atenção de estudos científicos de diferentes áreas de conhecimento como economia, administração e o direito, desta forma, a revisão do conhecimento com base epistemológica pode legitimar os estudos na área turística (NETTO; TRIGO, 2009).

Para Netto e Trigo (2009), turismo é campo de estudo, Beni (2001) o aborda através da Teoria Geral dos Sistemas, Molina (2003) interpreta o turismo por meio da fenomenologia, entre outros meios de observação e Boullón (2002) entende o turismo como um saber inserido nas ciências experimentais naturais, em suma, o debate teórico 
se o turismo é ou não uma ciência persiste no campo epistemológico (LOHMANN; NETTO, 2008). Campodónico e Chalar afirmam que "El turismo es esencialmente un campo de conocimiento transversal y em la actualidad no posee una malla disciplinar definida en el sentido tradicional del término" (2011: 1308). Na mesma linha, Moesch (2002) e Lohmann \& Netto (2008) apontam a dificuldade em se delimitar um método comum a todo estudo turístico, a ausência deste método enfraquece a consistência dos estudos, pois um autor pode rejeitar a metodologia utilizada por outros, por outro lado, essa mesma crítica pode promover a evolução do contexto científico.

Desta forma, para a compreensão do fenômeno turístico, diversas correntes se estabeleceram, análises positivistas, sistêmicas, funcionalistas, fenomenológicas, marxistas, hermenêuticas, entre outras.

Sendo assim, pergunta-se de que forma o sistemismo pode ser utilizado como método de análise para o turismo? Em busca de respostas para este questionamento, optou-se por consultar as obras relativas à temática a partir de autores como: Cooper, Shepherd e Westlake 2001; Cooper, Hall e Trigo 2011; Beni 2000; Lohmann e Netto, 2008; Netto e Trigo, 2009; Boullón 2002, entre outros.

A necessidade de utilizar essa abordagem se dá por conta da inviabilidade em se investigar problemas ou situações do turismo de modo isolado, uma vez que o fenômeno influencia e é influenciado dentro e fora do campo turístico.

Para contextualizar o surgimento da Teoria Geral dos Sistemas resgatou-se Ludwing Von Bertalanffy, pioneiro a discutí- la em 1973. Para o autor, um sistema é um todo integrado cujas propriedades não podem ser reduzidas apenas às propriedades de cada uma das partes.

O primeiro autor a formular um modelo sistêmico para o turismo foi Raymundo Cuervo, para ele, "a atividade turística seria um conjunto abarcando subconjuntos" como meios de comunicação, hospedagem, agências, guias, restauração e suvenires que a população flutuante consome (apud. LOHMANN; NETTO, 2008, p. 30).

Na sequência, Leiper define seu sistema com elementos comportamentais, geográficos, industriais e ambientais, com destaque nas relações entre a região emissora, a região de trânsito que interliga a origem aos destinos, a região receptora, o turista e a indústria de turismo e viagens (apud. Urano: 2016). Jost Krippendorf (2009) criou uma 
análise concentrada em entender a viagem no contexto histórico, levando em conta as necessidades de status e de realização pessoal do período e propôs um modelo sistêmico existencial da sociedade industrial, com base no conceito do desenvolvimento harmonioso do turismo e no viajar consciente.

Sérgio Molina (2003) aponta que o sistema turístico é formado pela superestrutura, a demanda, a infraestrutura, os atrativos, o equipamento e a comunidade receptora, com foco mais econômico objetivando a demanda, os gastos e necessidades do turista.

Outros autores como Mathieson \& Wall, Westlake, Mill \& Morrisson desenvolveram sistemas com componentes que envolviam a demanda, os transportes, a oferta, a política, o ambiente e a economia local, além do turista, capacidade de carga, mercado e até mesmo o marketing (apud. COOPER et. al, 2001).

Acerca do turismo contemporâneo, Cooper et. al (2011) descrevem um sistema envolvendo a região emissora, a rota de deslocamento, a região de destino e o ambiente. Beni afirma que o sistema turístico é aberto, realiza trocas com o meio que o circunda e, por extensão, é interdependente, nunca autossuficiente. Dessa forma, "cada variável em um sistema interage com as outras variáveis de forma tão completa que causa e efeito não podem ser separados" (BENI, 2001, p.15). Em concordância, Petrocchi (2001) afirma que o desempenho do sistema de turismo depende do desempenho de cada um dos elementos que o compõe, então, para organizar essas variáveis é necessário um referencial dinâmico, que as represente, compreendendo os complexos conjuntos de causas e efeitos, inter-relação e interdependência. Em resumo, o sistema turístico abarcaria: a cadeia produtiva do turismo, a demanda turística, os ambientes natural, cultural, econômico e social, o deslocamento, a oferta turística, a infraestrutura da localidade e a participação do poder público, chamada por Beni de superestrutura (2001).

É essencial avaliar que o sistema turístico precisa de esferas de observação, que para o mesmo autor, seriam: tamanho, determinado pelo número de unidades que compõem o sistema, a correlação entre as variáveis e a casualidade que apresentam (BENI, 2001).

Netto e Trigo afirmam que é preciso "explicar as bases do conhecimento turístico por meio de uma teoria que articule suas (multi) facetas" (2009, p.151), em 
conformidade, Boullón atesta que não existe uma única versão explicativa do Sistema Turístico, "há apenas um sistema, com várias facetas" (2002, p. 37).

Sendo assim, no que tange o sistema turístico, o brasileiro Mário Carlos Beni constituiu em 1997 o sistema mais amplamente aceito pela academia. Em seu estudo, os elementos compostos pelas relações ambientais, pelo conjunto da organização estrutural e pelo conjunto das ações operacionais no turismo são denominados: SISTUR (BENI, 2001).

Sua abordagem do Sistur explica a relação entre o turismo e as outras atividades humanas. Sua definição apresenta-o como:

Conjunto de partes que interagem de modo a atingir determinado fim, de acordo com um plano ou princípio; ou conjunto de procedimentos, doutrinas, ideias ou princípios, logicamente ordenados e coesos com intenção de descrever, explicar ou dirigir o funcionamento de um todo (BENI, 2000, p.5).

De modo geral, o autor liga as partes que coexistem no funcionamento do turismo, de modo semelhante e, por vezes coincidente, com outros autores comentados anteriormente. Contudo, Beni relaciona a organização estrutural e operacional com as relações ambientais, demonstrando a importância de outros elementos na promoção da atividade. Em sua fundamentação do Sistur destaca cinco elementos:

Os objetivos: organização do plano de estudos da atividade de turismo, fundamentando as hipóteses de trabalho, justificando posturas e princípios científicos, aperfeiçoando e padronizando conceitos e definições e consolidando as condutas de investigação para instrumentalizar análises e ampliar pesquisa; o ambiente: está fora do controle do sistema, mas também determina, em parte, o seu funcionamento; os recursos: são o reservatório geral, a partir do qual as ações específicas podem ser formadas, isto é, são os meios utilizados para desempenhar as tarefas; os componentes: são os subsistemas identificados nos conjuntos das relações ambientais, da organização 
estrutural e das ações operacionais do SISTUR; a administração: a criação de planos que envolvam os objetivos globais, o ambiente, a utilização de recursos e os componentes (BENI, 2001, p. 45-47).

A figura 1 ilustra em forma de modelo o que a citação descreve acima e servirá, posteriormente, como auxílio na elaboração do modelo aplicado à região em estudo.

Figura 1 - Modelo de Sistur proposto por Beni

Sistur - Sistema de Turismo. Modelo Teórico Referencial - Diagrama de Contexto. Tourism System. Theoretical Referential Model - Chart of the Context.

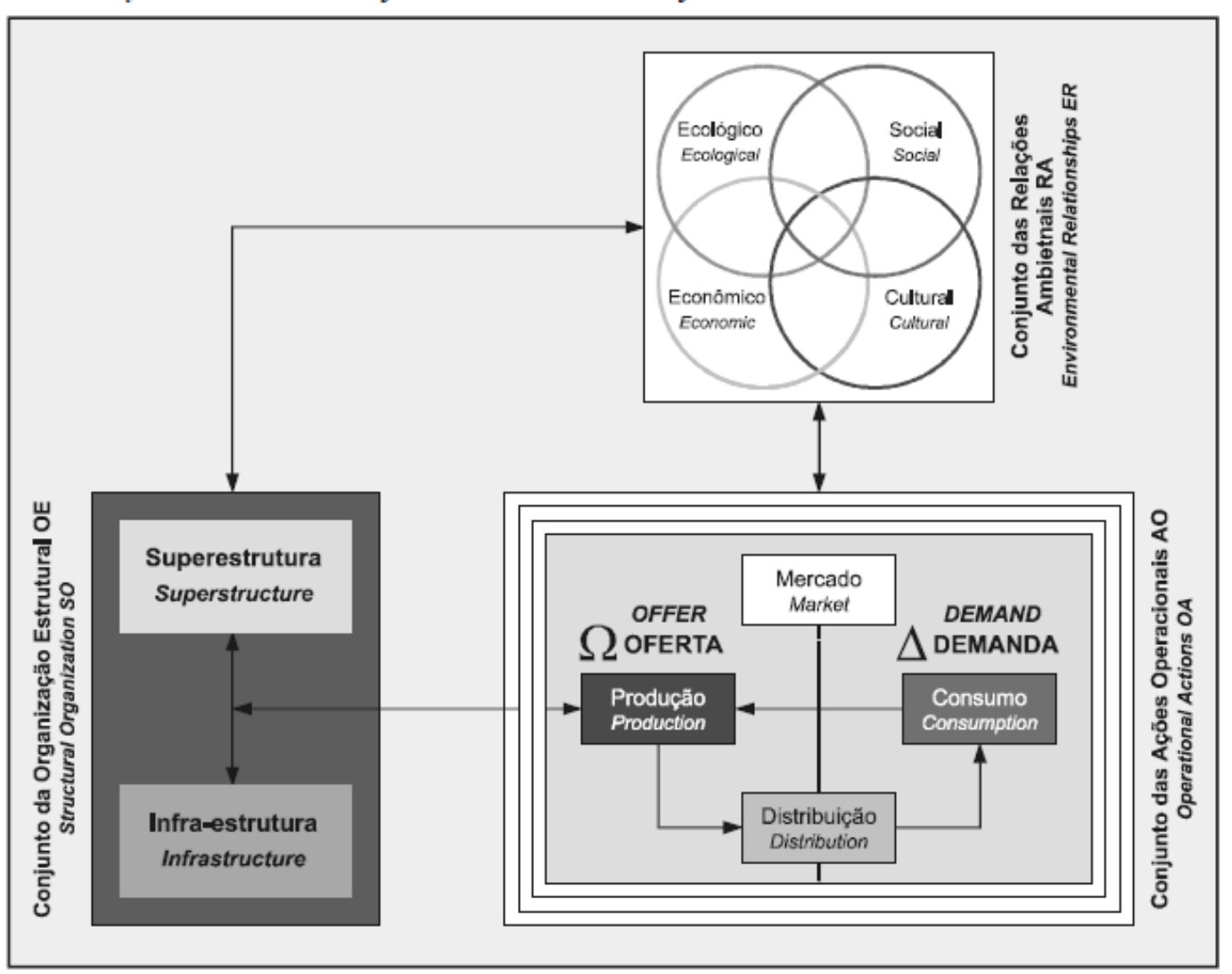

Fonte: Beni (2000, p. 49)

Ainda se encontram, entre as publicações relacionadas ao sistema turístico, outras abordagens e aplicações:

Quadro 1 - Diferentes abordagens e aplicações da teoria geral do sistema para análise do fenômeno turístico 


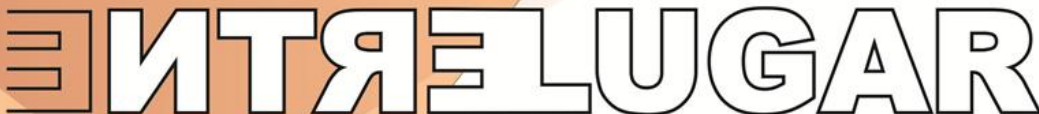

\begin{tabular}{|c|c|}
\hline \multicolumn{2}{|c|}{$\begin{array}{l}\text { Diferentes abordagens e autores para o uso da teoria geral dos sistemas aplicada } \\
\text { ao turismo }\end{array}$} \\
\hline 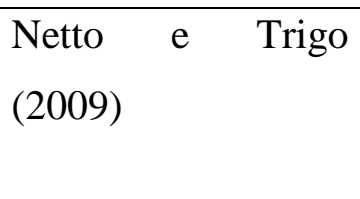 & $\begin{array}{l}\text { Abordam a dimensão multifacetada da atividade turística, que } \\
\text { requer a incorporação de instrumentos envolvidos por outras } \\
\text { áreas do conhecimento }\end{array}$ \\
\hline Pimentel et al, 2014 & $\begin{array}{l}\text { Interpretam como "o meio pode exigir do sistema turístico } \\
\text { respostas de funcionamento", em que o mundo globalizado } \\
\text { relaciona o ambiente e o sistema, supondo que exista um sistema } \\
\text { turístico internacional, nacional e regional/municipal }\end{array}$ \\
\hline Lobo (2011) & $\begin{array}{l}\text { Pontua que a regulação do sistema turístico depende da } \\
\text { capacidade de entropia do receptivo, esta influencia diretamente } \\
\text { as possibilidades de existência de um sistema turístico }\end{array}$ \\
\hline $\begin{array}{l}\text { Andrade e Netto } \\
(2003)\end{array}$ & $\begin{array}{l}\text { Usam o ponto de vista da administração para discutirem a face } \\
\text { empreendedora formada pela oferta de equipamentos e serviços } \\
\text { disponíveis no mercado e suas interfaces com a demanda } \\
\text { turística }\end{array}$ \\
\hline $\begin{array}{l}\text { Pimentel e Pimentel } \\
\text { (2012) }\end{array}$ & $\begin{array}{l}\text { Refletem acerta do planejamento e do controle da produção no } \\
\text { contexto da atividade turística, afirmando que o sistema turístico }\end{array}$ \\
\hline Nóbrega (2011) & $\begin{array}{l}\text { scute como o planejamento dos atores do sistema turístico } \\
\text { gem à sazonalidade }\end{array}$ \\
\hline Valduga (2008) & $\begin{array}{l}\text { Interpreta como o produto turístico transcende o valor monetário } \\
\text { estipulado e as relações ultrapassam a dinâmica da compra e } \\
\text { venda, de modo que o produto turístico torna-se um serviço, que, } \\
\text { transforma-se em uma experiência. }\end{array}$ \\
\hline Fernandes (2015) & $\begin{array}{l}\text { Com perspectiva antropológica, conecta os atores do sistema } \\
\text { turístico, através de um estudo etnográfico do setor turístico } \\
\text { regional, em particular do lado da oferta, com foco nos } \\
\text { promotores de serviços }\end{array}$ \\
\hline Anjos (2008) & $\begin{array}{l}\text { Propõe o planejamento do turismo caracterizando as dinâmicas } \\
\text { do sistema quanto aos fluxos econômicos e sociais da área em } \\
\text { questão. }\end{array}$ \\
\hline
\end{tabular}


Organização: das autoras (2018)

Nota-se a abrangência de aplicações e interpretações da teoria dos sistemas para o turismo, bem como sua versatilidade. Como o propósito deste artigo é apresentar o sistema turístico da linha da fronteira, optou-se pela utilização do modelo proposto por Beni (2001), usando como inspiração na elaboração do modelo, a atual Política Nacional de Regionalização do Turismo para Mato Grosso do Sul.

\section{CARACTERIZAÇÃO DA ÁREA DE ESTUDO SEGUNDO OS AMBIENTES SOCIAL E ECONÔMICO}

Em se tratando de uma região fronteiriça, a mesma apresenta um conjunto de múltiplas relações econômicas, sociais, políticas, culturais, pessoais, trabalhistas e muitas outras que se estabelecem num espaço binacional (SILVA, 2009). Essas interações espaciais derivam da vocação geográfica para o fluxo de pessoas, bens, serviços e informações que caracterizam a relação entre as cidades.

Sendo assim, no Estado de Mato Grosso do Sul, dos 79 municípios, 44 se encontram na faixa de fronteira internacional, e destes destacam- se 03 municípios cujas áreas urbanas fazem contato contíguo (fronteira seca), ou seja, são conurbações internacionais. De um lado cidades brasileiras e de outro, cidades paraguaias: Ponta Porã/Brasil e Pedro Juan Caballero/Paraguai; Coronel Sapucaia/Brasil e Capitán Bado/Paraguai, Paranhos/Brasil e Ypêjhú/Paraguai. O presente estudo compreendeu uma destas conurbações, a formada por Ponta Porã e Pedro Juan Caballero.

A cidade de Ponta Porã se localiza a $324 \mathrm{~km}$ da capital do Estado. As atividades econômicas que se destacam são a pecuária, agricultura, comércio e prestação de serviços. Com população estimada em 86.717 habitantes em 2015, um PIB de $\mathrm{R} \$ 21.209,86$ e IDH de 0,701 (IBGE, 2016).

Pedro Juan Caballero (PJC) é a atual capital jurídica e legislativa do Departamento de Amambay, localizado a $536 \mathrm{~km}$ da capital Asunción com clima subtropical úmido. População estimada em 140.866 habitantes e IDH: 0,665 (PEREIRA, 2016). 
$\mathrm{O}$ aspecto de destaque no contexto fronteiriço estudado está no fato das cidades/países estarem divididas apenas pelo canteiro central da Avenida Internacional, implicando em uma proximidade e circulação especialmente facilitada.

Figura 2 - Planta da conurbação Ponta Porã/BR e Pedro Juan Caballero/ PY.

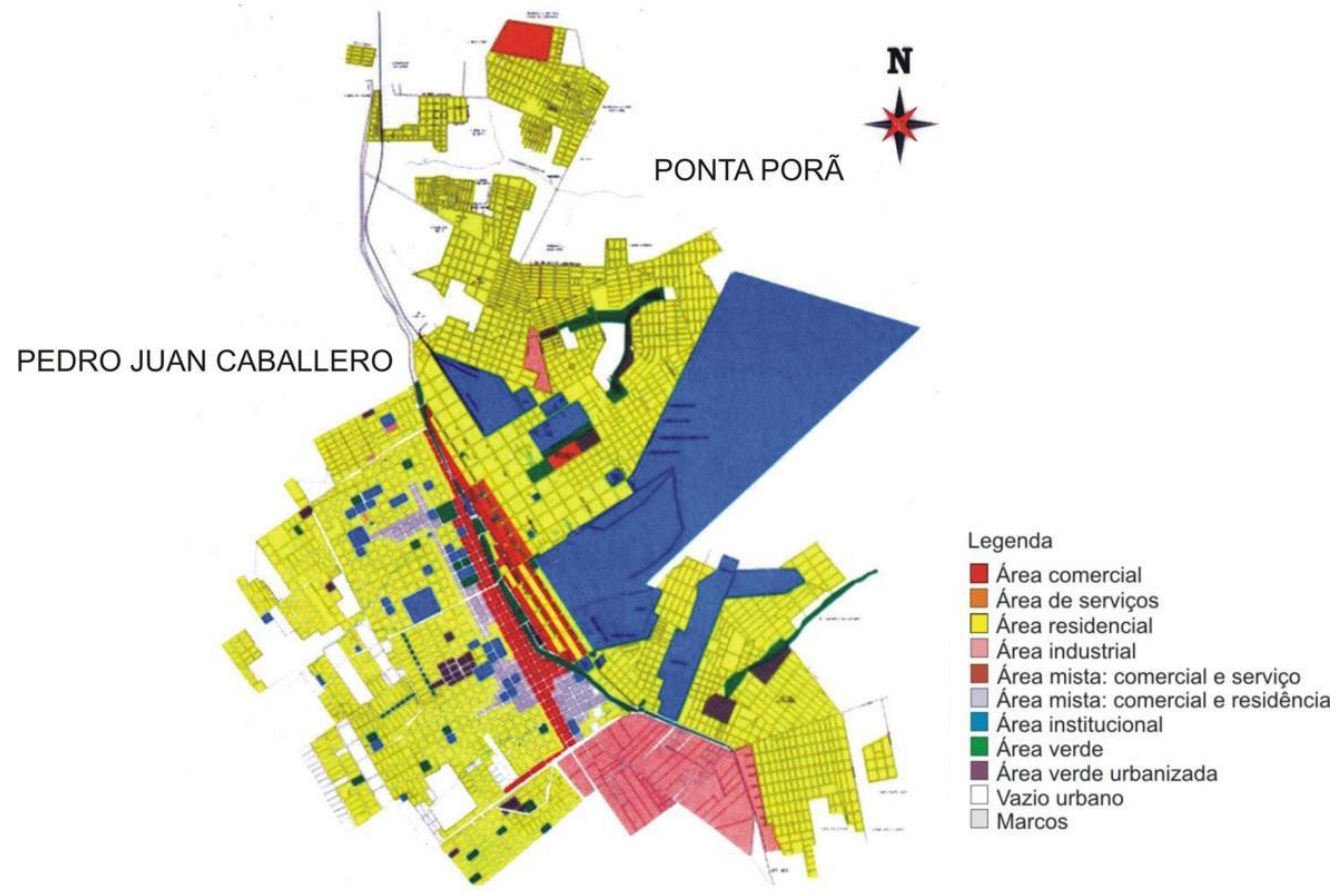

Fonte: Pereira (2014, p. 794).

Martins (2007) pontua que a venda de produtos movimenta um grande fluxo de pessoas desde a origem do município, consolidando a atividade turística com o passar dos anos. Deste modo, pode-se observar que a fronteira em si não é a principal atração para o turismo, mas sim as atividades que ali estão estabelecidas, a exemplo do turismo de compras de produtos estrangeiros.

Percebendo este contexto, o Ministério do Turismo lançou em 2011 o Frontur, programa de turismo de fronteiras, a ideia era incrementar o fluxo de turistas entre os países, auxiliar a preparação dos estados para os megaeventos de 2014 e 2016, fortalecer a formatação de roteiros turísticos integrados e aprimorar os sistemas de informações e de atendimentos dos portões de entrada. Entretanto, a cidade de Ponta Porã não foi incluída nas ações específicas do programa, privilegiando as cidades de Corumbá/MS e Foz do Iguaçu/ PR. 
Em junho de 2016 o Ministério do Turismo lançou uma nova categorização dos municípios das regiões turísticas do mapa do turismo brasileiro, fato este que reduziu o número de cidades turísticas no território nacional; em Mato Grosso do Sul o número caiu de 79 para 60 cidades turísticas, a Região Caminhos da Fronteira que contava com nove municípios ficou com apenas três, Ponta Porã, Antônio João e Laguna Carapã (BRASIL, 2016).

A seguir, apresenta-se o sistema turístico na linha de fronteira e todas as reflexões por ele impetradas.

\section{O SISTEMA TURÍSTICO DA LINHA DE FRONTEIRA PEDRO JUAN CABALLERO/PY E PONTA PORÃ/BR.}

O Estado de Mato Grosso do Sul tem pautado suas diretrizes de atuação em programas do governo federal que estão sendo implementados por todo país, especificamente o PNRT - Programa Nacional de Regionalização do Turismo².

A Secretaria de Cultura, Turismo, Empreendedorismo e Inovação (Sectei); o Fórum Estadual de Turismo; a Fundação de Turismo de Mato Grosso do Sul e o Fórum de Dirigentes de Turismo conformavam alguns dos principais elementos do sistema turístico de Mato Grosso do Sul, no que se refere ao elemento superestrutura. A figura 3 ilustra a organização político-administrativa do turismo em Mato Grosso do Sul em vigência até o primeiro semestre de 2018. Em junho de 2018 foi sancionada a Lei $\mathrm{n}^{\circ}$ 5.224 que estabelece normas sobre o Sistema Estadual de Turismo do Estado do Mato Grosso do Sul (SET-MS), as Políticas Públicas Estaduais para o Turismo e o Plano Estadual de Turismo foi publicada. Os espaços de coordenação coletiva, como o Fórum Estadual de Turismo e o Fórum Estadual de Secretários e Dirigentes de Turismo não estavam atuando há, no mínimo, dois anos. Mas em julho retomaram-se os trabalhos a partir de uma nova figura jurídica, o Conselho Estadual de Turismo, que veio substituir o Fórum Estadual de Turismo.

Figura 3 - Organização político-administrativa do turismo em Mato Grosso do Sul

\footnotetext{
${ }^{2}$ A premissa do Programa, centrou-se no propósito de que sua execução, de forma descentralizada e regionalizada, com foco no planejamento coordenado e participativo, repercutisse, positivamente, nos resultados socioeconômicos do território.
} 


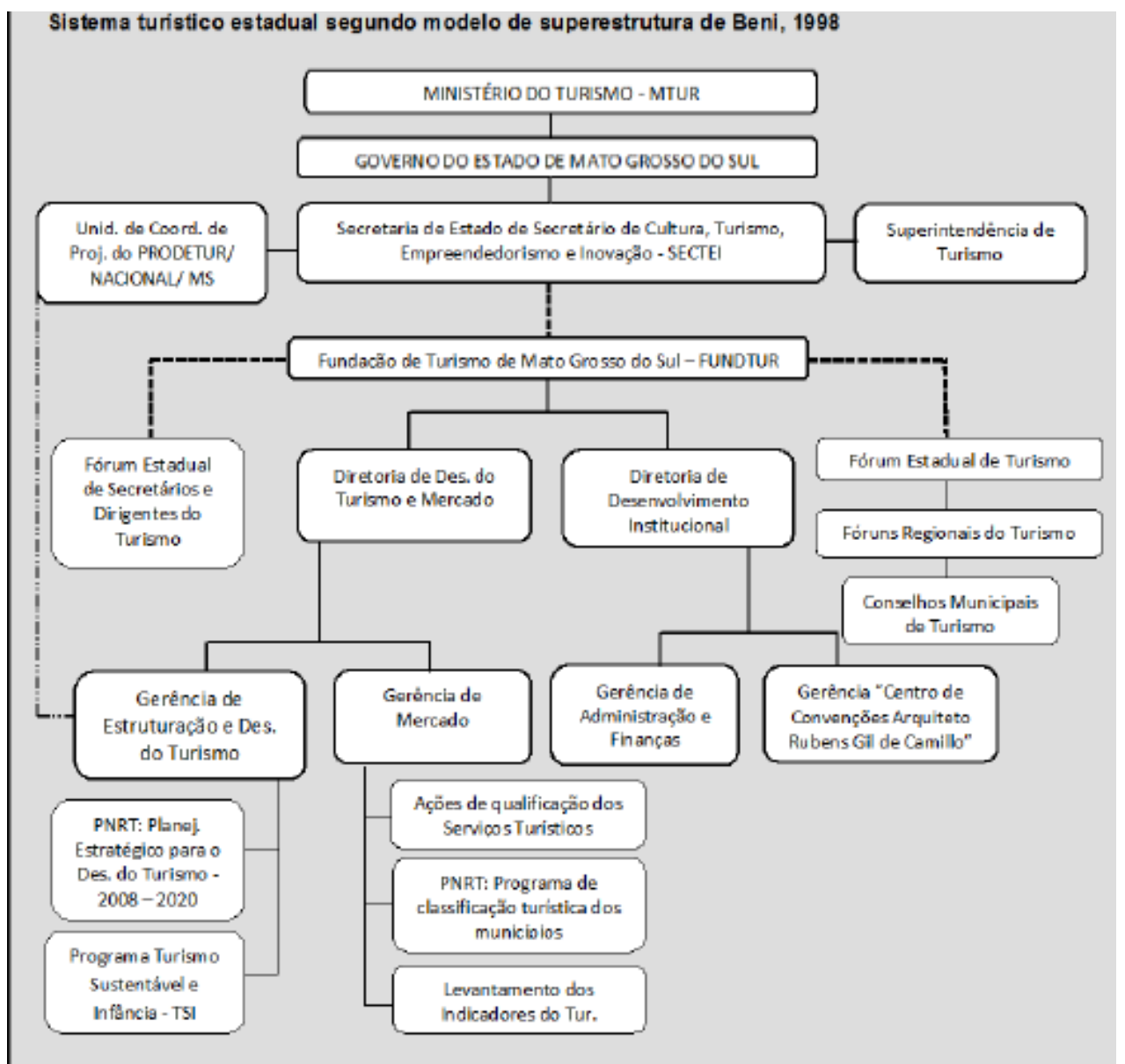

Fonte: Pereira (2016, p. 85). ${ }^{3}$

A seguir serão apresentados os elementos do sistema turístico proposto por Beni (2001) e aplicados ao território turístico da fronteira entre Ponta Porã e Pedro Juan Caballero, sendo eles: superestrutura, infraestrutura, oferta turística, demanda, mercado e distribuição.

\section{SUPERESTRUTURA}

Para o autor a superestrutura trata da "política oficial de turismo e sua ordenação jurídico- administrativa que se manifesta no conjunto de medidas de organização e de promoção dos órgãos e instituições oficiais", além das estratégias, planos ou programas que interferem no setor (BENI, 2000, p. 99).

\footnotetext{
${ }^{3}$ Atualmente (julho de 2018) o Fórum Estadual de Turismo assumiu o nome de Conselho Estadual de Turismo e está em vias de construir seu regimento. Mas o propósito é o mesmo do Fórum, servir de instância de governança para as discussões coletivas do turismo. Outra mudança refere-se à antiga SECTEI, hoje a pasta do turismo encontra-se na SEMAGRO.
} 
Este ordenamento político se manifesta em Ponta Porã através de dez secretarias municipais, a secretaria de turismo encontra-se junto à de indústria e comércio. Ainda relacionado ao turismo, destaca-se o Conselho Municipal de Turismo COMTUR (inativo) e o Convention \& Visitors Bureau binacional (C\&VB), também inativo. O município possui um Plano Diretor que contempla estratégias e ações para o desenvolvimento do turismo além de fazer parte do Fórum Regional Caminhos da Fronteira (FUNDTUR, 2014). O Fórum foi instituído em 2014 e faz parte do Programa Nacional de Regionalização do Turismo - PNRT.

A cidade de Pedro Juan Caballero, por sua vez, possui um coordenador de governança turística ligado à Secretaria Nacional de Turismo, e a secretaria municipal de Cultura, Deportes y Turismo, além da Camara de Industria Comercio y Turismo organização que representa empresas e empresários da fronteira.

No Brasil o órgão nacional de turismo está centralizado na figura do Ministério do Turismo, o que no Paraguai corresponde a Secretaria Nacional de Turismo (SENATUR). Em nível estadual, Mato Grosso do Sul possui uma secretaria (SEICTEI), na qual está ligada a Fundação de Turismo (FUNDTUR), enquanto o Paraguai possui o Departamento de Amambay (equivalente ao estado de Mato grosso do Sul no Brasil).

Nóbrega (2016) pondera em sua pesquisa que Ponta Porã possui fluxo turístico real, compara as dimensões das políticas públicas e de cooperação regional do município com os padrões do Programa 65 Destinos Indutores do MTur, identificando assim, uma carência de projetos e profissionais qualificados na estrutura pública local para aproveitar o potencial turístico observado em Ponta Porã.

O Paraguai possui o "Plan Nacional de Desarrollo", um de seus objetivos seria "expandir la capacidad del turismo receptivo, y propiciar el desarrollo en áreas de frontera" (Portal Informe Presidencial), além deste, há o Plano Nacional de Desenvolvimento do Turismo e uma plataforma de assessoramento técnico turístico no Portal da Senatur na qual é possível enviar propostas e receber orientação técnica. Também se encontra no mesmo portal o encarte das ações realizadas por esta secretaria, percebe-se a tentativa de ordenar, planejar, fomentar e formalizar o setor turístico do país através de projetos pontuais em cada região. 
Abaixo, figura ilustrativa da superestrutura turística do território fronteiriço produzido após o levantamento documental e bibliográfico acerca dos países e da fronteira.

Figura 4 - Superestrutura turística do território fronteiriço entre Ponta Porã - BR e Pedro Juan Caballero - PY

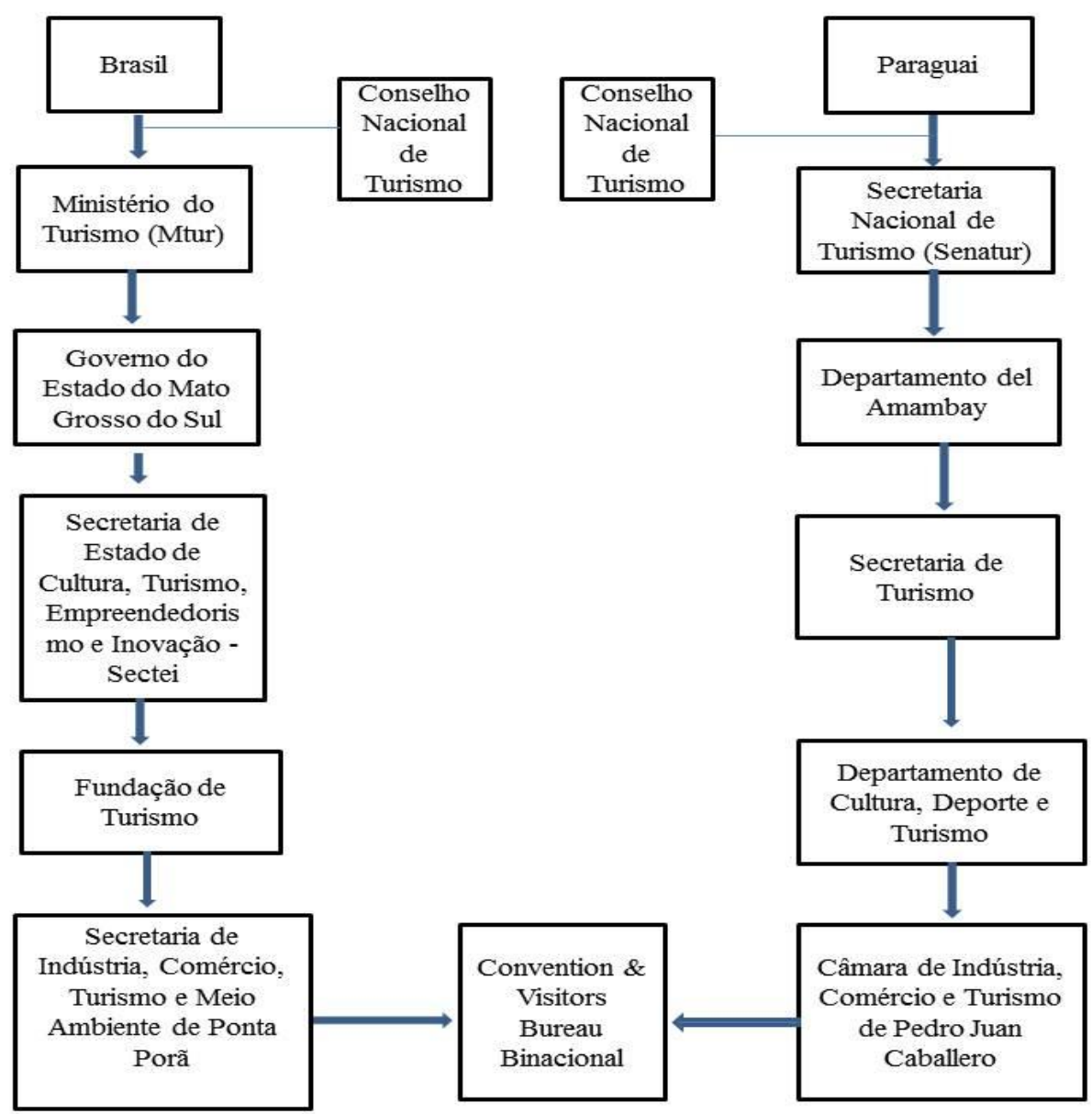

Fonte: Ribeiro (2016)

Ao observar o Sistema Nacional de Turismo Brasileiro, suas atribuições e atuação, nota-se que o governo paraguaio estabelece suas esferas hierárquicas de modo diferenciado, o Brasil possui 23 Ministérios, entre eles o Ministério do Turismo, no 
Paraguai são apenas 12, entretanto, as outras áreas são atendidas por Secretarias (20), entre elas, a Senatur - Secretaria Nacional de Turismo.

As semelhanças continuam ao passo que o Brasil possui um Plano Nacional de Turismo e o governo paraguaio possui um Plan Maestro de Desarrollo Sostenible del Sector Turístico, além de um plano de desenvolvimento nacional.

Dadas as proporções territoriais reduzidas em comparação ao Brasil, o Paraguai possui uma dinâmica de planejamento da atividade, não obstante, a efetividade da mesma não pode ser constatada, o que é possível ser feito no Brasil através dos dados, estimativas e sondagens disponibilizados no link "Dados e Fatos" no portal do Ministério do Turismo.

Enquanto os países são separados apenas pela Avenida Internacional, o Sem Fronteiras Convention \& Visitors Bureau, estando em funcionamento, estabeleceria um elo entre as nações, um meio binacional de promover, dialogar, fomentar e coordenar as atividades e atores relacionados ao turismo na fronteira. Criado em 2012, ainda está legalmente ativo e as propostas nele contidas consideraram tanto o empresariado de Ponta Porã quanto o de Pedro Juan Caballero, reforçando assim a integração de fronteira pretendida pela entidade.

\section{INFRAESTRUTURA}

Além de induzir parcerias e prover os investimentos necessários para o desenvolvimento da atividade, a administração pública possui, na esfera da infraestrutura, o papel de viabilizar os investimentos desde a infraestrutura urbana, rede viária e de transportes, telecomunicações, distribuição de energia, água, captação de esgotos entre outros, indispensáveis para que qualquer consumidor se disponha a viajar, além de se configurarem serviços essenciais aos moradores.

Ferreira (2016) buscou analisar a competitividade dos itens "infraestrutura geral, marketing e promoção do destino" do município de Ponta Porã levando em consideração o Programa 65 Destinos Indutores, lançado em 2008 e ainda vigente. A autora optou por esta metodologia, pois suas variáveis e critérios possibilitaram estabelecer parâmetros de comparação que levaram a constatar que nas dimensões escolhidas, Ponta Porã possui condições de competir com os destinos indutores estabelecidos pelo MTur. 
Na dimensão infraestrutura básica, a média Brasil em 2014 foi de 68,2 pontos, Ponta Porã registrou 56,5\%; acrescentou ainda que "a intensificação do comércio internacional impulsionou o desenvolvimento da infraestrutura turística e de apoio em ambas às cidades" (FERREIRA, 2016, p. 18).

Contudo, mesmo possuindo um aeroporto internacional, devido à sua posição estratégica de fronteira nacional, o aeroporto de Ponta Porã não recebe voos regulares, o mesmo acontece em Pedro Juan Caballero, que possui um aeródromo para receber voos particulares, este fato dificulta o acesso de maiores distâncias a ambas as cidades.

Oliveira (2012, p. 240) afirma em seu trabalho que Ponta Porã e Pedro Juan Caballero são "atualmente constrangidas pela precariedade das alternativas de transportes disponíveis, mesmo possuindo vocação acumulada no comércio e nos serviços"

Do lado paraguaio, o Plan Nacional de Desarollo nos traz alguns dados: existem saídas diárias de empresas de ônibus para o Brasil e Argentina, os cassinos atraem turistas internacionais, principalmente brasileiros, os 22.144 leitos disponíveis no país, dados de 2011, não são suficientes para satisfazer a demanda por isso existe uma perspectiva da instalação de novos hotéis; os Shopping Centers são de importância turística principalmente para os visitantes brasileiros e argentinos, e por fim, um dos três estádios para eventos esportivos do país está em Pedro Juan Caballero. Baptista (2016) complementa afirmando que existem condições favoráveis ao desenvolvimento de um arranjo produtivo local (APL) de turismo na região de fronteira, por possuir uma série de elementos que possibilitariam a estruturação e desenvolvimento do turismo.

\section{OFERTA TURÍSTICA}

Para Lage e Milone (2001, p. 72) "a oferta turística pode ser definida como a quantidade de bens e serviços turísticos que as empresas são capazes de oferecer a dado preço, em determinado período de tempo", em suma, atrativo turístico, equipamentos e serviços turísticos e a infraestrutura de apoio turístico; Beni (2001) complementa apontando detalhadamente, alojamento, alimentação, recreação e lazer, arte e cultura. 
Gonçalves (2016) procurou levantar na rede hoteleira em Ponta Porã de que forma ela pretendia responder as oscilações da moeda e da ocupação variável, por conta dessa característica, observou que o trade hoteleiro não dialoga, alguns empreendimentos participaram do $\mathrm{C} \& \mathrm{VB}$, dois hotéis possuem parceria com restaurantes, quatro com agências de viagens on-line e um possui parceria com taxistas.

Pereira (2014) contribui com informações no setor de gastronomia, apontando treze (13) estabelecimentos alimentícios do lado brasileiro e vinte e um (21) do lado paraguaio, um centro de convenções e treze (13) auditórios e salões para eventos, além de quatro (04) agências de viagens brasileiras. Já Ferreira (2016: 16), identifica que "o município possui treze (13) restaurantes, seis (06) agências de viagens e oito (08) hotéis". As opções de lazer vão desde o turismo de compras na fronteira seca com Pedro Juan Caballero/PY, até cassinos, ecoturismo com passeios ecológicos, turismo histórico/cultural.

Quanto a oferta de leitos, os registros do lado paraguaio são poucos, o site da associação industrial hoteleira do Paraguai possui 34 hotéis registrados, todos na capital Assunção, o site tripadvisor aponta 3 pousadas e 4 hotéis em Pedro Juan Caballero.

Mesmo com os dados acima mencionados, em sua pesquisa, Baptista (2016, p. 15) pondera que "quanto à dinâmica do emprego no setor turístico, Ponta Porã cresceu acima da média do estado e possui vantagem locacional e especialização no setor", revelando um potencial considerável.

\section{DEMANDA TURÍSTICA}

A atividade do turista no território receptivo implica em uma gama de transformações oriundas do seu consumo no local, este consumo pode ser compreendido como a aquisição de bens e serviços com o objetivo de satisfazer suas necessidades, caracterizando a existência de demanda turística. Lage e Milone (2001, p. 56) conceituam que a "demanda turística pode ser definida como a quantidade de bens e serviços turísticos que os indivíduos desejam e são capazes de consumir a dado preço, em determinado período de tempo". Beni (2001, p. 211) afirma que "as pessoas que se deslocam temporariamente de sua residência habitual, com propósito recreativo ou por outras necessidades e razões demandam a prestação de alguns serviços básicos”. Ignarra 
(2003) afirma que a demanda pode ser segmentada em efetiva e potencial. Para atender a demanda é fundamental que a localidade esteja preparada para oferecer aos visitantes mais do que atrativos, implica oferecer condições para que o turista permaneça pelo tempo escolhido e usufrua de infra- estrutura e serviços de qualidade.

Em se tratando de Ponta Porã, Gonçalves (2016) pontua que parte importante da demanda corresponde ao turista de negócios, representantes comerciais e empresariais, Pereira (2016) reflete que o turismo de compras em Ponta Porã pode não trazer o turista como hóspede, todavia, ele consome diversos serviços e o efeito multiplicador do turismo promove um desdobramento financeiro positivo.

O Ministério do Turismo do Brasil, juntamente com a Fundação Instituto de Pesquisas Econômicas (FIPE), publicou a pesquisa Caracterização e Dimensionamento do Turismo Internacional do Brasil, realizada anteriormente em 2010 e repetida em 2016, a pesquisa fornece subsídios para formulação de políticas públicas e para definição de estratégias de promoção turística do país no exterior, podendo otimizar a atração de turistas estrangeiros ao Brasil por Mato Grosso do Sul (BRASIL, 2017).

Quanto ao Paraguai, em 2015, a Senatur criou o Observatorio Turistico Nacional em cumprimento ao que previa em seu Plan Maestro de Desarrolllo Sostenible del Sector Turístico. O observatório se constitui como ferramenta de informação para conhecer a dinâmica, o crescimento e as variações do setor turístico, registrando em 2015, 23.144 turistas em Pedro Juan Caballero (PARAGUAI, 2015).

Em se tratando de número de turistas registrados, o anuário estatístico nacional pontua 77.000 turistas estrangeiros em Mato Grosso do Sul em 2016 (BRASIL, 2018), sem dados específicos para Ponta Porã.

\section{DISTRIBUIÇÃO}

Segundo Beni a distribuição seria o "conjunto de medidas tomadas com o objetivo de levar o produto ou o serviço do produtor ao consumidor” (2001, p. 181), abrangendo desde a estratégia de marketing, a programação de visitas, a seleção dos intermediários, a estimulação de vendas, o relatório e controle de vendas.

O portal da Senatur (Secretaria Nacional de Turismo do Paraguai) realiza a função de marketing do país, com destaque para natureza, cultura, história, golfe, pesca, 
tecnologia e compras, de todas as regiões, inclusive do Departamento de Amambay e de Pedro Juan Caballero.

Gonçalves (2016) reflete que a gestão do turismo na cidade deveria se dar de forma integrada entre a Secretaria Municipal, o C\&VB e o COMTUR, porém, estas duas últimas entidades encontram-se inoperantes. Ainda aponta que como promoção digital, Ponta Porã possui uma página com informações turísticas no facebook, além do aplicativo "Eventos da Fronteira", com informações importantes para o turista.

A municipalidade de Pedro Juan Caballero tem sua divulgação na página institucional $^{4}$ e a página do grupo Barcos y Rodados onde e possível ver os atrativos, local para comer e dormir. A Senatur promove o turismo interno através de vídeo institucional "Date una vuelta por tu país”, e veicula o vídeo promocional "Viví lo auténtico, Paraguay tenés que sentirlo”.

As cidades de Ponta Porã e Pedro Juan Caballero não possuem plano de marketing nem uma marca turística, e em sua pesquisa comparativa, na dimensão marketing e promoção do destino, Ferreira (2016) encontrou a pontuação de 47,3\% para Ponta Porã enquanto a média nacional era 48,4\% em 2014, nível considerado pela autora como regular, não obstante, o Mapa de Oportunidades de Pedro Juan Caballero aponta que o setor empresarial possui interesse em melhorar suas vendas com a produção de marketing, contudo, não há empresas especializadas na cidade (PARAGUAY, 2014).

Uma parceria do governo brasileiro forneceu tecnologia para que se criasse e regulamentasse o Registro Nacional de Turismo do lado Paraguaio, através do software REGISTUR, formou-se uma base de dados que pode ser observada no portal Senatur nos itens: agências, alojamentos extra hoteleiros, hoteleiros, comissionistas, consultores turísticos, arrendamentos de vehiculos, transporte turístico, guia, aventura, pesca, operadores, posadas, restaurantes, bares, eventos, turismo fluvia y lacustre (PARAGUAI, 2016)

\section{MERCADO}

\footnotetext{
${ }^{4}$ http://visitparaguay.travel/v1/ ;

http://www.bienvenidoaparaguay.com/ciudades.php? xmlcity $=210 \& x m l$ depto $=14$
} 
Para Lage \& Milone (2001), em todo sistema econômico, é necessário que o ser humano crie um mecanismo pelo qual possa resolver três problemas fundamentais: O quê? Como? E para quem produzir? Como qualquer outro mercado, a atividade turística permite aos agentes econômicos: consumidores (turistas) e provedores (empresas de turismo) tomarem decisões para resolverem os problemas econômicos fundamentais.

O mercado turístico pode ser classificado em direto, no qual se oferecem e consomem bens e serviços relacionados ao turismo, e indireto, onde se oferecem e consomem bens e serviços parcialmente relacionados ao turismo (LAGE, MILONE, 2001; DIAS, 2005; IGNARRA, 2003; BENI, 2001).

Entendendo os compradores como turistas, e os vendedores os atores do mercado, estes elementos podem estabelecer uma competição perfeita, imperfeita, oligopólio e monopólio, Beni (2001) fala na estrutura de mercado monopsônio e concorrência. No contexto pesquisado pode-se quase afirmar que temos uma situação de mercado imperfeita, caracterizada como monopsônio, uma vez que o comércio do lado paraguaio depende quase, exclusivamente, da demanda brasileira.

Segundo o Mapa de Oportunidades disponibilizado pelo Sebrae em seu portal, o setor que ainda gera mais valor no município é o de Comércio e Serviços contribuindo com 53\% do PIB, levando em consideração que o turismo se enquadra neste setor. O setor agropecuário apresentou expressiva participação no valor da produção de 2012, contribuindo com cerca de 20\% do PIB municipal. O Sebrae (2016) ainda enxergou carências e sugere oportunidades para empreender no município em: agência de turismo, artesanato com produção de souvenirs, empreendimentos de lazer para o turismo, especialidades médicas, estacionamentos, exploração do geoturismo histórico, exploração do turismo agrícola, lojas de free shop, hotéis, gastronomia regional, spa urbano. Das onze sugestões, seis estão diretamente relacionadas ao turismo; contudo, outra pesquisa, realizada pela Fecomércio (2011), aponta que a região que apresenta menor concentração de empresas no estado do Mato Grosso do Sul é a região de Ponta Porã, este dado expõe a fragilidade da região e a dependência da agricultura.

\section{CONCLUSÃO}


A atividade turística deve ser analisada como um conjunto de amplas relações, apresentando interações com o ambiente econômico, social, político, ecológico, tecnológico, entre outros. Faz- se necessária a ação conjunta da iniciativa privada, do poder público e da comunidade local.

Um exemplo de ação abrangente foi a realização do projeto "MS SEM FRONTEIRAS" por parte do SEBRAE - Fundación CIRD (Centro de Informações e Recursos para o Desenvolvimento-), Fundación Trabalho e Empresa - Bolívia e com apoio do FOMIN (Fundo Multilateral de Investimentos) e BID- Banco Interamericano de Desenvolvimento), que de 2011 a 2015 atendeu em torno de 2.500 pequenos negócios na região de fronteira no Brasil e Paraguai através de consultorias, capacitações e palestras.

Espera-se que, sendo o turismo uma atividade em constante crescimento, seja compreendida pelos governantes como uma aliada para o incremento da economia de suas nações.

Observando o conteúdo documental reunido, pode-se afirmar que a Teoria Geral dos Sistemas contempla os elementos, atores e relações que a atividade turística estabelece com poder público, sociedade e iniciativa privada. A análise destes elementos e de suas relações colocam em evidência os potenciais e as carências, a exemplo do que se verificou a presença do documento norteador para o planejamento do turismo no Paraguai, através do seu Plan Nacional de Desarrollo, embora não se observe a efetivação dos seus propósitos e o acompanhamento deles não está disponível. Ressalta-se que Ponta Porã e Pedro Juan Caballero não possuem inventário turístico, o que possibilita novas pesquisas nesse sentido.

Considera-se, então, que o enfoque sistêmico proporciona um olhar abrangente, holístico e crítico, acerca dos elementos envolvidos com a atividade turística, permitindo assim uma melhor análise e planejamento de ações futuras. Fica claro com a pesquisa documental que os elementos superestrutura, infra-estrutura e cadeia produtiva do turismo precisam fortalecer as relações entre si para que o elemento "demanda" possa ser melhor aproveitado como input para o funcionamento do sistema. Além disso, verificou-se total carência na disponibilidade de um banco de dados amplo, sistematicamente alimentado e específico para esta região, apontando a necessidade de ações nesta direção, as quais seriam responsabilidade do elemento superestrutura de 
ambos os municípios. De todos os elementos do sistema turístico proposto por Beni, o mais fragilizado neste território de fronteira seria a superestrutura e em segundo lugar a infra-estrutura. Com o aprimoramento de políticas e condições básicas de realização do turismo a demanda automaticamente seria estimulada. Os elementos oferta e distribuição já vem se autogerindo ao longo das décadas, mesmo com pouco estímulo governamental e sistemáticas interrupções de mandatos. Resta insistir na indicação de fortalecimento do Convention Binacional como espaço de coordenação cooperada com potencial para assumir o protagonismo no que se refere à superestrutura de turismo neste território de fronteira.

\section{REFERÊNCIAS BIBLIOGRÁFICAS}

\section{ALBUQUERQUE, J. L. C. Fronteiras em Movimento e Identidades Nacionais: a} imigração brasileira no Paraguai. Tese (Doutorado). UFCE: Fortaleza, 2005.

AMAMBAY. Gobierno Departamental Pedro Gonzalez. Pedro Juan Caballero. Disponível em: http://www.amambay.gov.py/index.php/2014-04-24-19-00-38/2014-0424-19-16-04/pedro-juan-caballero. Acesso em: 20 jun.2016.

ANDRADE, R.O. B. de; NETO, L. M. A Gestão Privada do Turismo. In: TRIGO, L. G. G. (org.). Turismo: como aprender, como ensinar. São Paulo: Senac, 2003.

ANJOS, F. A. dos; HENZ, A. P.; LEITE, F. C. de L. Planejamento e Território: a aplicabilidade de um modelo sistêmico para Porto Belo (SC). SeminTur V Seminário de Pesquisa em Turismo do Mercosul. Universidade de Caxias do Sul- UCS/ RS. 2008. Disponível em: $<<$ http://www.ucs.br/ucs/tplVSeminTur\%20/eventos/seminarios_semintur/semin_tur_5/ trabalhos/arquivos/gt08-01.pdf >>. Acesso em: 04 nov. 2015.

BAPTISTA, Lis Thamirys D., PEREIRA, Cristina Horst, SONAGLIO, Cláudia Maria. Dinâmica do setor turístico em Ponta Porã - MS, Brasil. Revista Iberoamericana de Turismo - RITUR, Penedo, vol. 6, n.2, p. 118-137, 2016.

BENI, M. C. Análise Estrutural do Turismo. São Paulo: Senac, 2001.

BENI, M. C. Política e Estratégia do Desenvolvimento Regional: roteiro metodológico com base na instrumentação e operacionalização do Sistur - Sistema de Turismo Aplicado ao Projeto Costa Oeste: estudo de caso. Turismo - Visão e Ação - ano 2 - n.3 - p.51-70 abr/set -2000 . 
BERTALANFFY, Ludwig von. Teoria Geral dos Sistemas. Petrópolis: Vozes, 1973. BOUllón, R. C. Planejamento do Espaço turístico. Bauru, SP: Edusc, 2002.

BRASIL, Ministério do Turismo. Programa de Qualificação a Distância para o Desenvolvimento do Turismo. Curso de Segmentação do Turismo: Conceitos básicos. Apoio à comercialização de produtos. Brasília: 2009. Disponível em: << http://www.turismo.gov.br/turismo/programas_acoes/regionalizacao_turismo/Curso_Se gmentacao_Distancia_EAD.html >. Acesso em: 08 abr. 2015.

BRASIL, Ministério do Turismo. Ministério Cria Programa de Estímulo ao Turismo de Fronteira. Publicado: Segunda, 29 de Agosto de 2011, 17h08. Portal Ministério do Turismo. Disponível em: $\quad$ http://www.turismo.gov.br/\%C3\%BAltimasnot\%C3\%ADcias/4587-mtur-cria-programa-de-estimulo-ao-turismo-defronteira.html >>, Acesso em: 20 jun.2016.

BRASIL. Ministério do Turismo. Secretaria Nacional de Políticas de Turismo. Departamento de Estruturação, Articulação e Ordenamento Turístico. Coordenação Geral de Regionalização. Programa de Regionalização do Turismo/ Diretrizes. Brasília 2013. 47 páginas. Disponível em: $<<$ http://www.turismo.gov.br/images/programas_acoes_home/PROGRAMA_DE_REG IONALIZACAO_DO_TURISMO_-_DIRETRIZES.pdf >>. Acesso em: 04 Set. 2016. BRASIL. Ministério do Turismo. Estatísticas e Indicadores Turismo no Mundo 2013. Disponível em: < http://www.dadosefatos.turismo.gov.br/dadosefatos/estatisticas_indicadores/estatisticas _indicadores_turismo_mundial/ >>. Acesso em: 14 abr. 2015.

BRASIL. Ministério do Turismo. Boletim de Desempenho Econômico do Turismo. Ano XI no 44. LOCAL: Fundação Getúlio Vargas - FGV, 2014. Disponível em: < http://www.dadosefatos.turismo.gov.br/dadosefatos/conjuntura_economica/boletim_des empenho_turismo>. Acesso em: 23 abr. 2015.

BRASIL. Ministério do Turismo. Caracterização e Dimensionamento do Turismo Internacional no Brasil - 2012-2016. Relatório Descritivo 2012 - 2016. FIPE, São Paulo, 2017.

BRASIL. Ministério do Turismo. Anuário Estatístico de Turismo - 2017. Ano Base 2016. Disponível em: http://dadosefatos.turismo.gov.br/2016-02-04-11-53-05.html. Acesso em: 12/06/2018. 
COOPER, C.; HALl, C. M.; TRIGO, L. G. G. Turismo Contemporâneo. Rio de Janeiro: Elsevier, 2011.

CAMPODÓNICO, R.; CHALAR, L. Hacia la Construccion Del Conocimiento en Turismo. Revista Studios e Perspectivas en Turismo. Volumen 20 (2011) pp.13071323.

http://www.estudiosenturismo.com.ar/PDF/V20/N06/v20n6a05\%20res.pdf >. Acesso em:03 fev.2016.

COOPER, C.; SHEPHERD, R.; WESTLAKE, J. Educando os Educadores em Turismo: manual de educação em turismo e hospitalidade. São Paulo: Rocca, 2001.

CORRÊA, C. C.; MARIANI, M. A. P. Estudo da Implantação da Atividade do Turismo e a Análise das Possibilidades de Desenvolvimento Regional e Local: o caso do município de Costa Rica/MS. Disponível em:< http://www.sober.org.br/palestra/15/297.pdf>. Acesso em: 30 abr. 2015.

DIAS, R. Introdução ao Turismo. São Paulo: Atlas, 2005.

FECOMERCIO. Federação do Comércio de Bens, Serviços e Turismo do Estado de Mato Grosso do Sul. Estudo sobre a Competitividade nos Setores de Comércio, Serviços e Turismo em Mato Grosso do Sul: Perspectivas até 2020. Campo Grande/MS: FECOMERCIO/MS - SEBRAE/MS, 2011, 156 p.

FERREIRA, C. S. Infraestrutura Básica, Marketing e Promoção: a competitividade destes indicadores em Dourados e Ponta Porã/MS, a partir dos critérios do Projeto 65 Destinos Indutores. Dourados: UEMS, 2016. Trabalho de conclusão de curso (especializacao) - Planejamento e Gestão Pública e privada do Turismo - UEMS, 2016.

FERNANDES, F. Os Estudos dos Sistemas Turísticos e a Antropologia. Madeira: um estudo de caso. Pasos Revista de Turismo y Patrimonio Cultural. Vol 13 (2015). n.2. Special Issue. Pp. 425-434. ISSN 1695-7121. Disponível em:< http://www.pasosonline.org/en/articulos/779-o-estudo-dos-sistemas-turisticos-e-aantropologia-madeira-um-estudo-de-caso $>$. Acesso em: $\langle 05$ mai.2015>.

FUNDTUR. Fundação de Turismo de Mato Grosso do Sul. Gerência de Estruturação e Desenvolvimento do Turismo / Diretoria de Desenvolvimento do Turismo e Mercado Fundação de Turismo de Mato Grosso do Sul. 24/03/2014. Disponível em: << http://www.turismo.ms.gov.br/wp- 
content/uploads/sites/54/2015/04/INSTANCIAS_GOVERNANu00C7A_MS.pdf >>. Acesso em: $<<11$ set. $2016>>$.

GONÇALVES, L. R. R. O Turismo e a Rede Hoteleira na Fronteira Internacional de Ponta Porã-MS/Brasil e Pedro Juan Caballero/PY. Monografia Especialização em Planejamento e Gestão Pública e Privada do Turismo. Ponta Porã: UEMS. 2016. IBGE. Instituto Brasileiro de Geografia e Estatística. Informações Estatísticas de Ponta Porã- MS. Disponível em:

http://cidades.ibge.gov.br/xtras/perfil.php?codmun=500660. Acesso em: 12 mai.2016. IGNARRA, Luiz Renato. Fundamentos do Turismo. 2.ed. São Paulo: Pioneira, 2003 KRIPPENDORF, J. Sociologia do turismo. Para uma nova compreensão do lazer e das viagens. São Paulo: Aleph, 2009.

LAGE, B. H. G.; MILONE, P. C. Economia do Turismo. São Paulo: Atlas, 2001.

LOBO, H. A. S. Princípios de Incerteza, Estado Estacionário e Evolução Espaço Temporal na Análise Sistêmica das Relações Socioambientais no Turismo. Revista Brasileira de Pesquisa em Turismo. n.6 (1). (2012) Pp.95-108. ISSN 1982-6125. Disponível em:< https://www.rbtur.org/rbtur/article/view/410 >. Acesso em:<09 out.2015>.

LOHMANN, G.; NETTO, A. P. Teoria do Turismo: conceitos, modelos e sistemas. São Paulo: Aleph, 2008.

MARTINS, P. C. S. A formação do território turístico de Pedro Juan Caballero (Paraguai). Dissertação de Mestrado. Aquidauana: UFMS, 2007.

MOLINA, S. O Pós Turismo. São Paulo: Aleph, 2003.

MOESCH, M. M. Para Além das Disciplinas: o desafio do próximo século. In: GASTAL, S. (org.); BENI, M. C.; CASTROGIOVANNI, A. C. Turismo Investigação e Crítica. São Paulo: Contexto, 2002.

MUNICIPALIDAD, Pedro Juan Caballero. Organograma Institucional. Disponível em: $<$ http://www.municipalidadpjc.gov.py/organigrama.php $>$. Acesso em:28 mai.2016.

NETTO, A. P.; TRIGO, L. G. G. Cenários do Turismo Brasileiro. São Paulo: Aleph, 2009.

NÓBREGA, R. F. Indicadores na Análise das Políticas Públicas de Turismo e da Cooperação Regional: um estudo de Ponta Porã e Dourados - Mato Grosso do 
Sul/BR. Dourados, MS: UEMS, 2016. 18p. Monografia (especialização) - Planejamento e Gestão Pública e Privada do Turismo - Universidade Estadual de Mato Grosso do Sul, 2016.

NÓBREGA, J. M. da. Estrutura de Referência para o Planejamento Turístico com Base na Abordagem Sistêmica e na Lógica da Gestão de Operações. Dissertação de Mestrado. Universidade Federal da Paraíba- UFPB/BC. João Pessoa, 2011. CDU 658.5 (043).

OLIVEIRA, Marcio Gimene de. As cidades gêmeas Ponta Porã - Pedro Juan Caballero e Foz do Iguaçu - Ciudad Del Este Diante das Des-Articulação Regional Sul-Americana. Tese (Doutorado): UFRJ, 2012

OMT. Introdução ao Turismo. São Paulo: Roca, 2001.

PARAGUAY. Mapa de Oportunidades de Negócios: grandes oportunidades para micro, pequeños y medianos negócios em Pedro Juan Caballero. Fundación Cird, 2014.

PARAGUAI. Presidência da República. Plan Nacional de Desarrollo: Paraguay 2014-2030. Disponível em: http://www.informepresidencial.gov.py/paraguay-2030plan-nacional-de-desarrollo. Acesso em: 20 jun.2016.

PARAGUAI. Secretaria Nacional de Turismo. Resumen de Políticas em Gestión Institucional.

Disponível

em: $<<$

http://www.senatur.gov.py/index.php?option=com_content $\&$ view=article\&id=435\&Ite mid=445>>. Acesso em: 10 jun.2016.

PARAGUAI. Secretaria Nacional de Turismo. Proyetos Turisticos: asesoramiento técnico turístico.

Disponível

em: http://www.senatur.gov.py/index.php?option=com_content $\&$ view=article \&id=509\&Ite mid=453. Acesso em:01 jun.2016.

PARAGUAI. Observatório Turístico Nacional. Estadísticas. Según via de acceso. Disponível em: https://www.senatur.gov.py/index.php/servicios/observatorio-turisticonacional. Acesso em: 12/06/2018.

PEREIRA, C. H. O desenvolvimento e o planejamento público do turismo em Mato Grosso do Sul. Dissertação (Mestrado) - Desenvolvimento Regional e Sistemas Produtivos. Ponta Porã, MS: UEMS, 2016.

PETROCCHI, M. Gestão de Pólos Turísticos. São Paulo: Futura, 2001. 
PIMENTEL, M. P. C.; PIMENTEL, T. D. Planejamento e Controle na Produção do Turismo: um ensaio. E\&G Revista Economia e Gestão. V.12, n.28, 2012. ISSN 19846606.

Disponível

em:<

http://www.ucs.br/ucs/tplVSeminTur\%20/eventos/seminarios_semintur/semin_tur_7/gt 04/arquivos/04/03_48_15_Carvalho_Pimentel >. Acesso em: $<03$ set.2015>.

PIMENTEL, M. P. C.; PIMENTEL, T. D.; CARRIERI, A.de P. Autopoiese e Sistema Turístico. Revista Acadêmica Observatório de Inovação do Turismo. Vol. VIII, n.1, 2014. ISSN 1980-6965. Disponível em:< http://bibliotecadigital.fgv.br/ojs/index.php/oit/article/view/32091 >. Acesso em:<10 out.2015>.

SEBRAE. Mapa de Oportunidades de Mato Grosso do Sul. Disponível em:<< http://www.sebrae.com.br/sites/PortalSebrae/ufs/ms/artigos/mapas-de-oportunidadespara-o-seu-municipio,a8032b487fcf0510VgnVCM1000004c00210aRCRD>>. Acesso em 11 de ago. 2016.

SILVA, R. M. Articulações Transfronteiriças: o caso da conurbação Ponta Porã e Pedro Juan Caballero. Dissertação de Mestrado. Aquidauana: UFMS, 2009.

URANO, D. G. Contribuições de Leiper, Wahab e Cuervo para a abordagem sistêmica do turismo. Revista de Turismo Contemporâneo- RTC, Natal, v. 4, Ed. Especial, p. 77-95, abr. 2016. Disponível em: < https://periodicos.ufrn.br/turismocontemporaneo/issue/viewIssue/504/74>>. Acesso em: $<<11$ ago. 2016>>.

VALDUGA, V. Do Modelo Sistêmico Linear Turístico ao da Unitas- multiplex. Uma Análise Crítica da Corrente Sistêmica e Suas Limitações no Campo Turístico. SeminTur V Seminário de Pesquisa em Turismo do Mercosul. Universidade de Caxias do Sul- UCS/ RS. 2008. Disponível em: < http://www.ucs.br/ucs/tplVSeminTur\%20/eventos/seminarios_semintur/semin_tur_5/tra balhos/gt05>>. Acesso em: $<05$ set.2015>.

WTO, UNWTO. Tourism Highlights. 2016 Edition. Disponível em:<< http://www.eunwto.org/doi/pdf/10.18111/9789284418145>>. Acesso em: 10 set. 2016. 
Aceito para publicação em novembro de 2018 